\title{
Land Subsidence Potential Detection in Yogyakarta International Airport using Sentinel-1 Insar Data
}

\author{
Dewanto, B.G ${ }^{1,2^{*}}$, Haryanto, Y., ${ }^{3,5}$, and Purnomo, S.N ${ }^{4,5}$
}

\begin{abstract}
On January 27, 2017, the Indonesian Government started building a new international airport in Yogyakarta Province, named Yogyakarta International Airport (YIA) to replace Adisucipto International Airport. YIA is located near the beach, which means that an awareness of natural disasters, such as coastal flooding, is essential. One of the causes of sea water flooding is land subsidence phenomenon. This land subsidence phenomenon can be monitored by using Sentinel-1 Interferometric Synthetic Aperture Radar (InSAR) data. To monitor the crustal deformation, the data used in this research are from years 2016-2019. The data were processed through LiCSBAS software which is published by the COMET in the UK. In the processing scheme, interferograms with many unwrapping errors are detected and removed via loop closure. Reliable time series and velocities are extracted using several noise indices, with the help of masking. The results show the subsidence phenomenon in the YIA area (up to $25 \mathrm{~mm}$ ).
\end{abstract}

Keywords: Deformation; land subsidence; YIA; Sentinel-1 InSAR Data; LiCSBAS.

\section{Introduction}

Airports are critical component of the aviation network. They play an important role, not only within the macro transport environment, but also in enhancing the quality of life and the regional economies, which are directly involved in the production of wealth [1]. Evans [2] stated that airports offer all of the requisite facilities for moving passengers and freight from surface to air transportation systems and for airlines to be able to take off and land their aircraft. Airports are much more than just places for flights, corporate transit events or tax free shopping; they are one of the biggest investments for cities and regions. In the heart of the regions in which they are located, and in certain sectors of activity (e.g. tourism), airport infrastructure is of the upmost importance. Due to new market demands and trends arising in related sectors, such as the aviation industry, their positioning has been changed in recent years.

\footnotetext{
1 Department of Geodetic Engineering, Faculty of Engineering Universitas Gadjah Mada, Yogyakarta, INDONESIA.

${ }^{2}$ Center for Disaster Studies, Universitas Gadjah Mada, Yogyakarta, INDONESIA

${ }^{3}$ Department of Civil Engineering, College of Engineering, National Cheng Kung University, TAIWAN

${ }^{4}$ Department of Hydraulic and Ocean Engineering, National Cheng Kung University, TAIWAN

${ }^{5}$ Department of Civil Engineering, Faculty of Engineering, Jenderal Soedirman University, INDONESIA

*Corresponding author; Email: bondan.g.d@ugm.ac.id
}

Note: Discussion is expected before November, $1^{\text {st }} 2021$, and will be published in the "Civil Engineering Dimension", volume 24, number 1, March 2022.

Received 13 July 2020; revised 13 March 2021; accepted 07 April 2021
Yogyakarta is an economic, tourist, and cultural city that has great potential. The city attracts tourists, both local and international. The present international airport, Adisucipto Airport, is too small and unable to serve large aircraft. Thus, the Government has reacted to this issue by building a new, more feasible airport: Yogyakarta International Airport (YIA). The new airport is in the sub-district of Temon, which is a large region in Kulon Progo, near the beach. It is located in the west of the Central Java frontier, Temon Kulon Progo. District Kulon Progo is one of the most vulnerable districts on the Indian Ocean in terms of tsunami disaster impacts [3]. This risk arises because the area between the IndoAustralian Plates (Figure 1) and the very active Eurasian plate lies on the coast of Kulon Progo Regency. A tectonic earthquake source that may cause tsunamis can occur in the subduction area of the South Java Sea [4-6].

Owing to several factors including groundwater depletion, underground mines, rapid land growth, and natural hazards, land subsidence has been a global issue over the past decades. This can happen gradually and becomes evident whether geological or human activities cause the land subsidence [7]. Land subsidence occurs in more than 150 countries worldwide, particularly in densely populated metropolitan areas, including major cities in China [8], Japan [9], Italy [10], Mexico [11], and Indonesia [12].

Satellite observation is a crucial source of Earth data that enables to monitor the effects of natural disasters, in particular. Data collection in inaccessible locations, the broad coverage that allows a full 


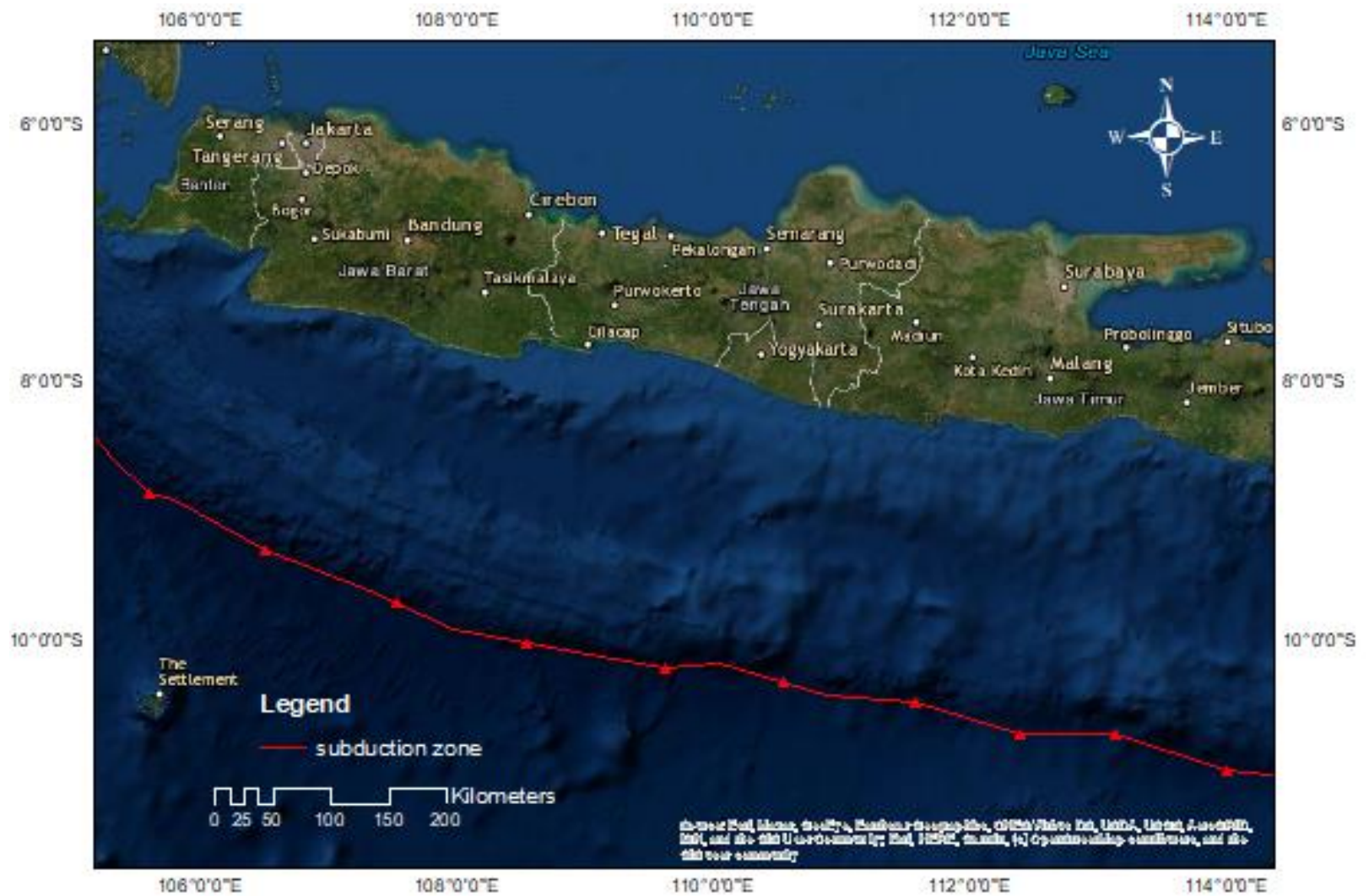

Figure 1. The Subduction Zone Location Relative to Java Island

analysis of world phenomena and the availability of long-standing historical data for wide areas allows all of the phenomena to be temporarily studied. This has many advantages over other monitoring techniques which provides more cost-effective and easier data collection. Interferometric Synthetic Aperture Radar (InSAR) has been developed as an efficient geodetic survey technique and is used in the geophysical investigation of earthquakes, landslides and other geological processes [13]. The InSAR technology can also monitor the deformation of the ground.

Spatial-temporal decorrelation and delay in air typically affect InSAR measurement accuracy [14]. It has been suggested that, persistent scatter interferometry (PS-InSAR) and Small Baseline subset InSAR (SBAS-InSAR) can be used to improve accuracy. In addition to the spatial and temporal decorrelation, the SBAS-InSAR system eliminates the phase decontamination and errors in the atmosphere. It could, therefore, have reliable characteristics for a time series deformation [15].

The European Space Agency (ERS)-1/2 satellite radar data were used by Manunta et al. [16] to detect largescale deformations in Rome, Italy and the SBAS method demonstrated its ability to obtain similar information from aerial, low-resolution data, leading to the identification of various major displacement sites. From 1992 to 2010, Zeni et al. [17] used SBAS technology with full resolution for a broad range of ground deformity measurements and observed potential deformation in historical buildings in Rome. Their findings demonstrate the efficient detection and monitoring of historic and artistic monuments by a two-scale SBAS-InSAR multi-sensor system. Xu et al. [18] used an ENVISAT Advanced Synthetic Aperture radar (ASAR) to review the coastal vertical land recycling movements in Shenzhen, to acquire them by ascending and descending orbit methods. They noticed a major coastal shrinkage $(25 \mathrm{~mm} /$ year $)$ in the recovered property.

Scientists at Soekarno-Hatta International Airport, Singapore Changi Airport, and Kuala Lumpur International Airport have previously carried out a study focussing on the deformation monitoring of airports using InSAR data [19-20]. $\mathrm{Ng}$ et al. [19] explained that the area of settlement at SoekarnoHatta International Airport (and surrounding industrial area, which is located between Kalideres and Cengkareng) forms a subsidence bowl. Field subsidence was also found by Radhi [20], at the International Airport of Kuala Lumpur, and Singapore Changi Airport.

Based on the above, in this research we would like to monitor the crustal deformation observed at YIA in the field with Sentinel-1 InSAR analysis for the period of 2016-2019. From the InSAR data in the YIA area, the output is the time series and velocity field of the deformation. 


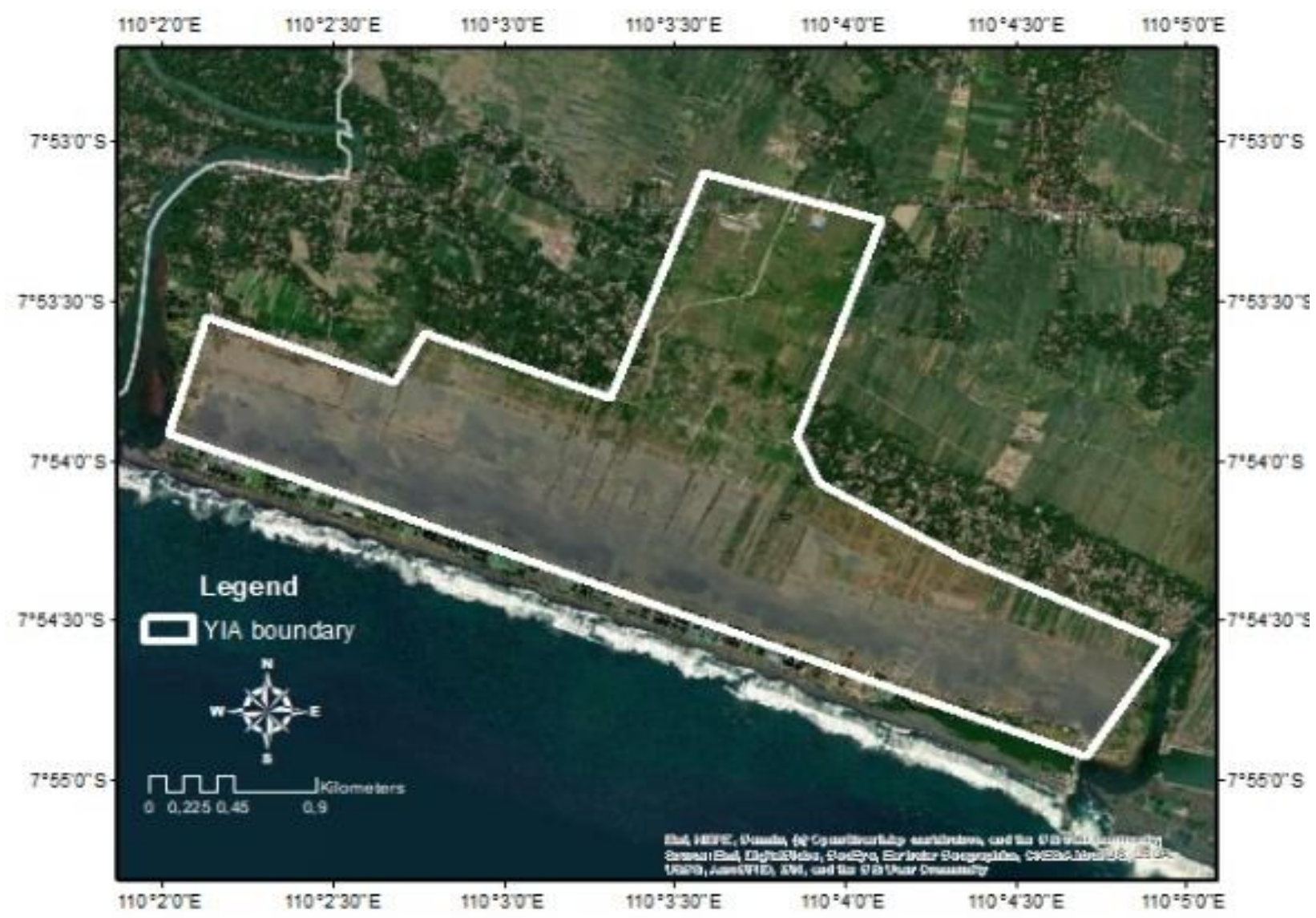

Figure 2. Study Area: White Line Defines the Boundary of the YIA Area

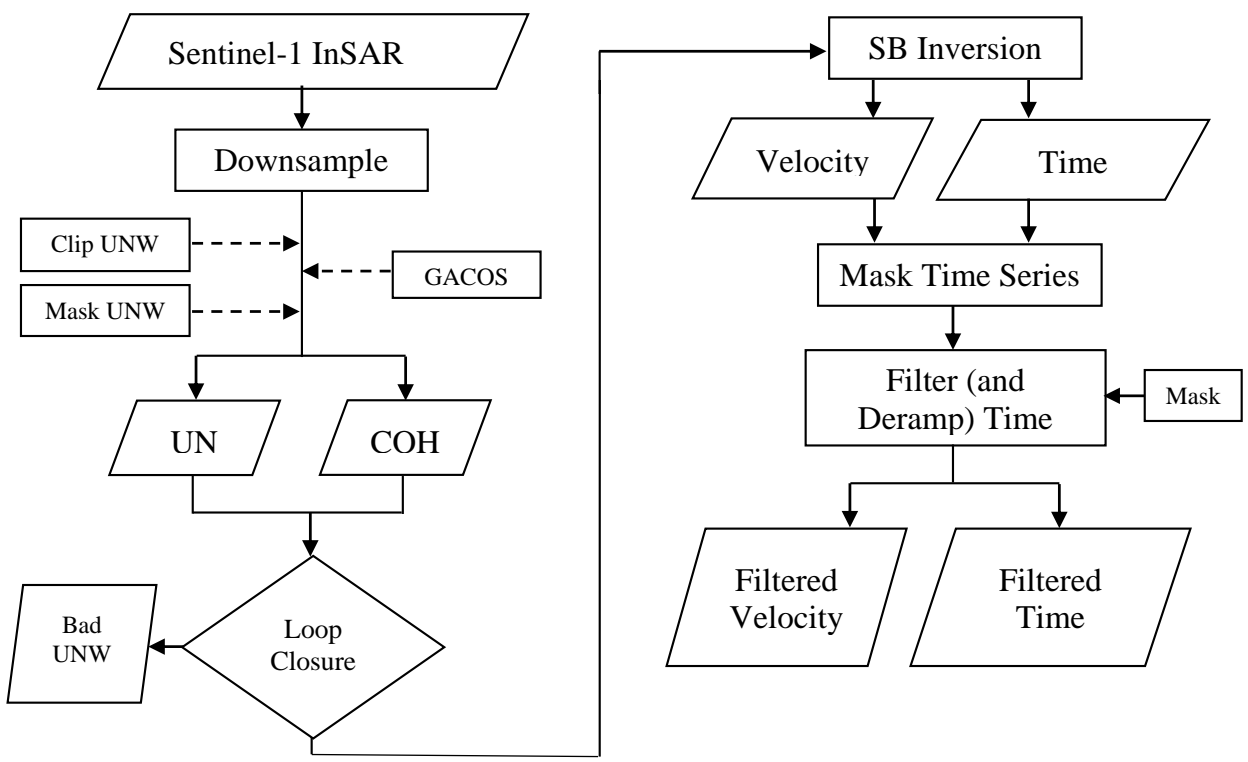

Figure 3. Research Workflow

\section{Data and Methodology}

The Yogyakarta International Airport in Temon (Kulonprogo district, province of Yogyakarta, Indonesia) is the area of study for this research. The data used here are InSAR 2016-2019 Sentinel-1 data, which have been downloaded from the COMET-LiCS web portal (https://comet.nerc.ac.uk/comet-lics-portal/). The frame ID used is 076D 09725121107 , which in descending direction and covers the area around Central Java Province. Figure 2 shows the field of study. The authors used $110.12^{\circ} \mathrm{E}, 110.55^{\circ} \mathrm{E},-8.17^{\circ}$ 
$\mathrm{S}$ and $-7.72^{\circ} \mathrm{S}$ as the boundary co-ordinates of the study area. The total number of InSAR images in this study are 121 and the research workflow is shown in Figure 3.

In Figure 3, the dashed lines denote optional steps to incorporate correction of the atmosphere (generic atmospheric online correction service, GACOS), masking and clipping. Before the small baseline inversion (SB), tests were carried out for incorrectly unwrapped interferograms to produce velocities and time series. The final products were further masked and filtered.

In order to process the Sentinel-1 InSAR data, the authors used the LiCSBAS software, published by Morishita et al. [21]. The LiCSBAS workflow of InSAR time series processor was divided into two main sections: preparation of a stack of unwrapped data and time series analysis. LiCSBAS began downloading LiCSAR products for the region of interest and this was followed by a data format conversion. To improve precision and efficiency of the processing, tropospheric noise correction using the InSAR (GACOS) external Generic Atmospheric Correction Online [22] data and unwrapped data masking/clipping were optional measures. Due to the accuracy and coverage of unwrapped data and control of the loop closure, incorrect unwrapped data was detected and disposed of in the time series study. GACOS uses the ITD model 25, which generates high resolution zenith total delay charts, to be used for correcting InSAR calculation and other applications, in order to derive layer and turbulence signals from tropospheric total delays. Due to its precision, and coverage of unwicked data, and by testing the closure of the loop, erroneously unwrapped data was identified and discarded during the time series analysis. With regard to SB interferograms, unwrapped phases are generally reduced in the STD for each interferogram (from an average of 6.7 to $4.2 \mathrm{rad}$ from 6.0 to a median rad 3.9) which shows that the GACOS correction considerably reduced the tropospheric noise [21].

The refined stack of unwrapped data was inverted for time series and speed displacement, followed by calculation of the STD and noisy pixels, based on multiple noise indices. Finally, a spatiotemporal filter was applied to the time series in order to eliminate the residual noise and extract the filtered time series and speed.

In LiCSAR processing chains, Interferograms are automatically created on the predefined LiCSAR frame base (usually 13 explosions at each of the IWS sub-swaths corresponding to a $250 \mathrm{~km} \times 250 \mathrm{~km}$ area). A second subsidiary image (close to the latest image for coherence preservation), which was already recorded (if available) with an enhanced method for spectral diversity, was used to copy newly acquired data into one primary image [23]. For each acquisition with three prior acquisitions and three subsequent acquisitions, interferograms would then be used, by default, although the amount may be increased in future. Interferograms are spatially filtered with an alpha-value of 1.0 adaptive spectrum filter from the GAMMA software [21], to eliminate noise. They are multilooked with an interface factor of $20 \mathrm{x} 4$ in range $\mathrm{x}$ azimuth (46 x $56 \mathrm{~m}$ spacing).

SBAS-InSAR is commonly used for the identification of subsidence, on the basis of the following equations:

$\frac{N+1}{2} \leq M \leq N\left(\frac{N+1}{2}\right)$

$\Phi_{j}(x, r)=\Phi\left(t_{B}, x, r\right)-\Phi\left(t_{A}, x, r\right)$

$\approx \Delta \Phi_{\text {disp }}+\Delta \Phi_{\text {topo }}+\Delta \Phi_{\text {orb }}+\Delta \Phi_{\text {atm }}+\Delta \Phi_{\text {noise }}$

Equation (1) is a quantity range of $\mathrm{M}$ differential interferograms, produced in the same area by a $\mathrm{N}+1$ SAR image at a specified time $\left(t_{0}, t_{1}, \ldots, t_{n}\right)$. Furthermore, Equation (2) represents the interferometric composition of the $\mathrm{j}$ (to be generated with two images in $t_{B}$ and $t_{A}$ ) interferogram phase in pixels $(\mathrm{x}, \mathrm{r})$, where $\mathrm{x}$ and $\mathrm{r}$ are the azimuth and range coordinates, respectively. The change in distance from the target to the radar along the sight line (LOS) causes the phase $\Delta \Phi_{\text {disp }}$. Moreover, the phases of $\Delta \Phi_{\text {topo }}, \Delta \Phi_{\text {orb }}, \Delta \Phi_{\text {atm }}$, and $\Delta \Phi_{\text {noise }}$ are created through the ground and satellite orbit, the atmospheric effect (and other noise), and, in particular, the effect of tropospheric delay. In order to achieve the deformation process $\Delta \Phi_{\text {disp }}$ function, SBAS-InSAR removes the residual components from the interferometric phase.

An SB inversion was performed on the interferogram network to estimate the velocity of a surface pixel over time, based on a series of displacement results. It is assumed that a stack of M-unwrapped interferograms $d=\left[d_{1}, \ldots, d_{M}\right]^{T}$ were rendered from $N$ images acquired at $\left(\mathrm{t}_{0}, \ldots, \mathrm{t}_{\mathrm{N}-1}\right)$ incremental displacement vector $\mathrm{m}=\left[\mathrm{m}_{1}, \ldots, \mathrm{m}_{\mathrm{N}-1}\right]^{\mathrm{T}}$ (i.e. $\mathrm{m}_{\mathrm{i}}$ is the incremental displacement between time $\mathrm{t}_{\mathrm{i}-1}$ and $\mathrm{t}_{\mathrm{i}}$ ) and can be extracted by solving Equation (3):

$d=G m$

where $\mathrm{G}$ is a $M x(N-1)$ zero architecture matrix, representing the interferogram network relationship with incremental displacements, given that the unwrapped interferogram (i.e. displacement between two acquisitions) is the sum of the corresponding incremental displacements [24]. Cumulative displacements (i.e. time series for displacement) are determined by summing up the incremental 
displacement for each acquisition. The mean displacement velocity is then calculated on at least the quadrature of the cumulative displacements.

The NSBAS approach was adopted [25], which imposes a temporary limitation to obtain the more practical time series of the displacement even with a disconnected network.

$$
\left.\left[\begin{array}{l}
\mathbf{d} \\
\mathbf{0}
\end{array}\right]=\left[\begin{array}{ccccccc}
{[} & & \mathbf{G} & & & \mathbf{0} & \mathbf{0} \\
1 & 0 & \ldots & \ldots & 0 & -t_{1} & -1 \\
\vdots & \ddots & \ddots & & \vdots & -t_{2} & \vdots \\
1 & \ldots & 1 & \ddots & \vdots & \vdots & \vdots \\
\vdots & & \vdots & \ddots & 0 & \vdots & \vdots \\
1 & \ldots & 1 & \ldots & 1 & -t_{N-1} & -1
\end{array}\right]\right]\left[\begin{array}{c}
\mathbf{m} \\
v \\
c
\end{array}\right]
$$

If $\mathrm{Y}$ is the scaling (weighting) element in the temporal constraints, a linear displacement $(\mathrm{d}=\mathrm{vt}+\mathrm{c})$ is assumed. The solution within the linked components of the network is minimally influenced by the low time limit (e.g. 0.0001). The time restriction component, therefore, only affects the connection via network gaps. Equation (4) can be employed for pixels with fully connected networks and those with gaps.

\section{Results and Discussion}

\section{Sentinel-1 InSAR Unwrapped Phase}

The downsample will be the one-precision floating point formats of the GeoTIFF file process with no header, in order to further analyze the time series and downsamples (multilooks) data, when set by -n option. Figure 4 provides examples of unwrapped phases. The entire Sentinel-1 InSAR unwrapped process is explained in Figure 4a, while the unwrapped process of the clip using the YIA area is shown in Figure 4b.

\section{Loop Closure and Mask Time Series}

Unwrapped data may include unwrapping errors, which can cause significant errors in the derived time series and should therefore be removed or corrected beforehand. Several approaches have been proposed to identify and correct unwrapping errors, taking advantage of the redundancy of a network of interferograms and loop phase closure. Fortunately, there are no interferograms in this case (which have major unwrapping errors) and they are now removed. This phase generates the mask with the aid of several noise indices, obtained in previous steps for the time series and speed of displacement. If the value for a pixel of any noise indicator is greater or smaller than the threshold specified, the pixel is masked. Figure 5 shows the time series of the mask. In this figure, the average number of coh_avg are constant, $n \_$unw is

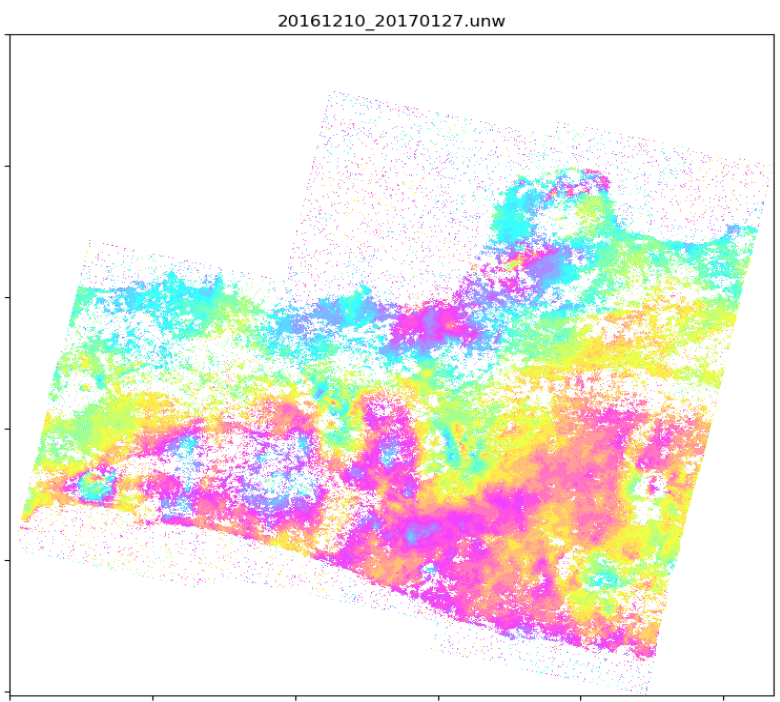

(a)

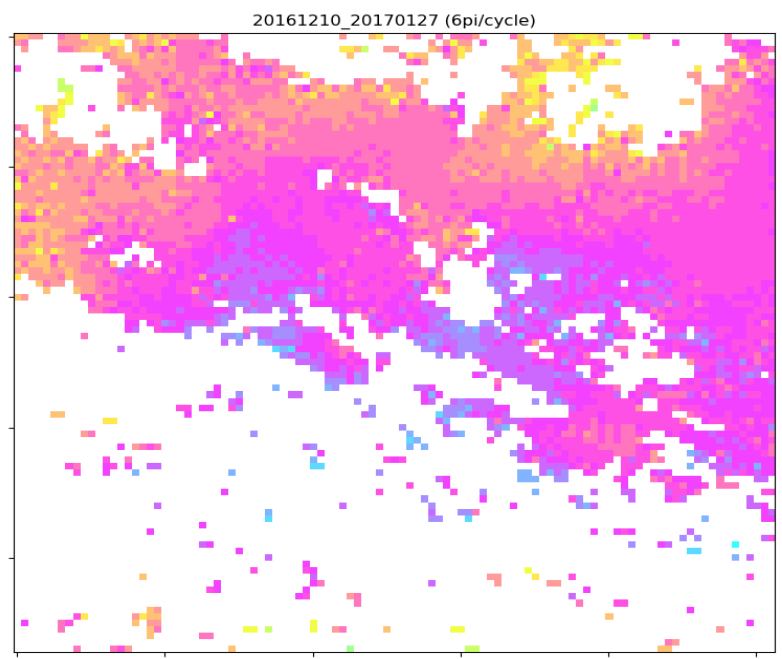

(b)

Figure 4. Unwrapped Data: (a) Full Unwrapped Phase of Sentinel-1 InSAR Frame 076D_09725_121107, and (b) Unwrapped Phase of the Clip using the Particular Region Around the YIA Area

the number of unwrapped data, vstd is standard deviation in velocity $(\mathrm{mm} / \mathrm{yr})$, maxTlen is the maximum time of linked network (year), $\mathrm{n}$ gap is the number of gaps in the network, and stc is spatiotemporary coherence $(\mathrm{mm})$. The masked/unmasked velocities could be seen in the top row and the other pictures being noise indices. The number shown in the brackets next to the noise index titles is the limit used.

\section{Time Series and Velocity Field Analysis}

The derived time-series also contains a number of noise-related conditions, such as residual tropospheric noise, ionospheric noise, and orbital errors. An isolation of these components from the displacement time series is possible with a space-time 

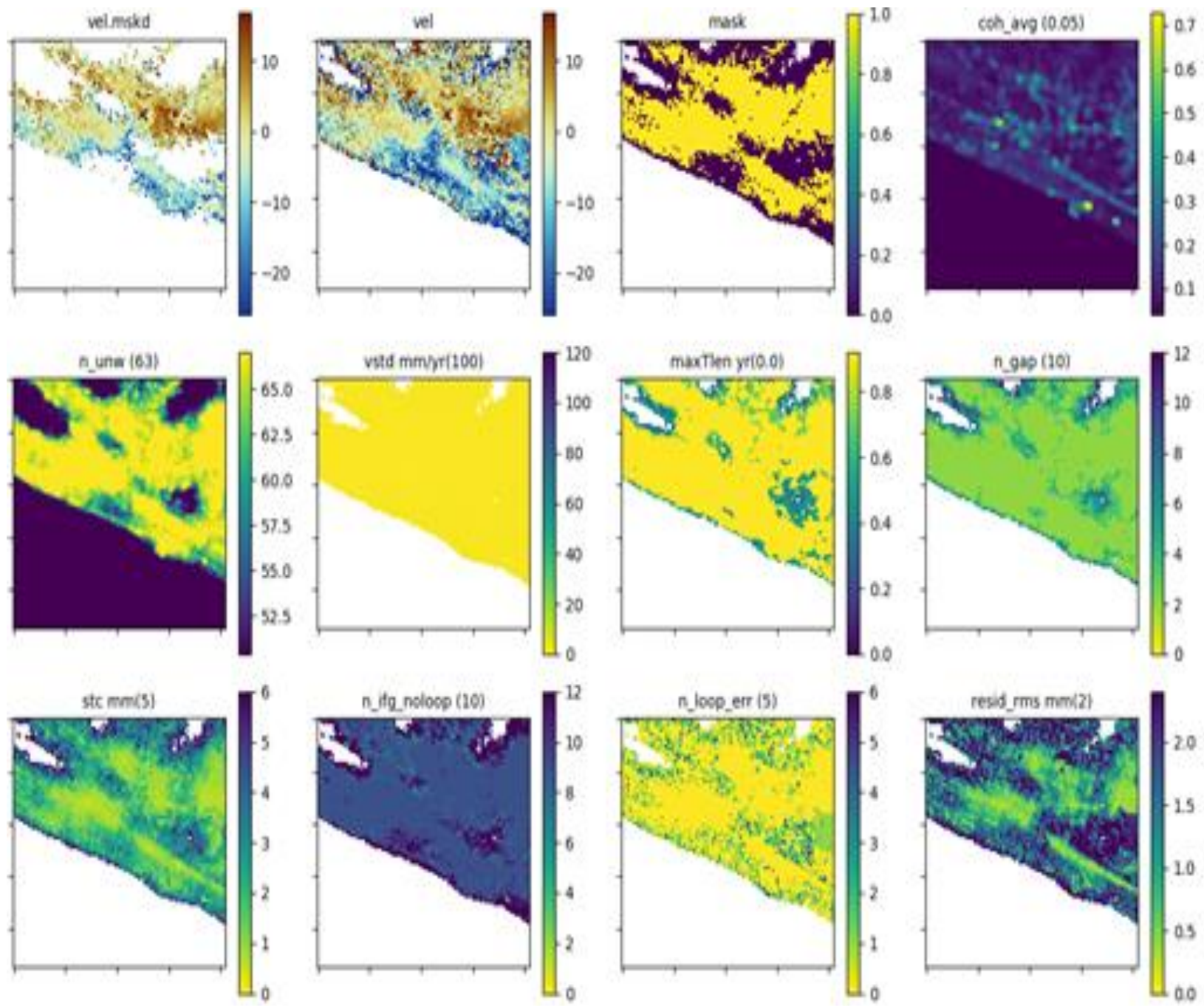

Figure 5. The Mask Time Series

filter (i.e. high-pass time and low-pass space) [26]. In order to complete this filtering, the authors added a single, two dimensionals Gaussian kernel in time and space.

As an interactive time-series display, LiCSBAS has two windows (graphical user interfaces). The first image window shows dimensions, cumulative deformation velocity and noise indexes (Figure 6). From Figure 6, it can be seen that there was uplift deformation in the northern part. However, the southern part (near to the beach) is dominated by land subsidence. The uplift deformation is affected by the Menoreh Mountains, while the land subsidence near to the beach is affected by the Sunda Megathrust activity, which subducted under the Eurasian Plate. The corresponding time series, with and without a space time filter, is drawn in Figure 7 immediately when a pixel of interest is clicked (black dot which is shown in Figure 6).

Figure 7 shows the time series of black dot (see Figure 6 ) which means land subsidence is $\sim 25 \mathrm{~mm} / \mathrm{yr}$. Figure 8 clarifies the distribution of the pattern of deformation at Yogyakarta International Airport. This figure provides a reference map from google maps for understanding the result of deformation, according to the specific location. Deformation range is typically between $-48 \mathrm{~mm} / \mathrm{yr}$ and $36 \mathrm{~mm} / \mathrm{yr}$. The standard deviation of the deformations is $0.1 \mathrm{~mm} / \mathrm{yr}$. YIA's main deformation processes comprise ground subsidence. This is especially dangerous for the airport, as this area has a high risk of natural disasters. YIA has a high risk of tsunami disaster, based on work carried out by Fauzi et al. [27]. 


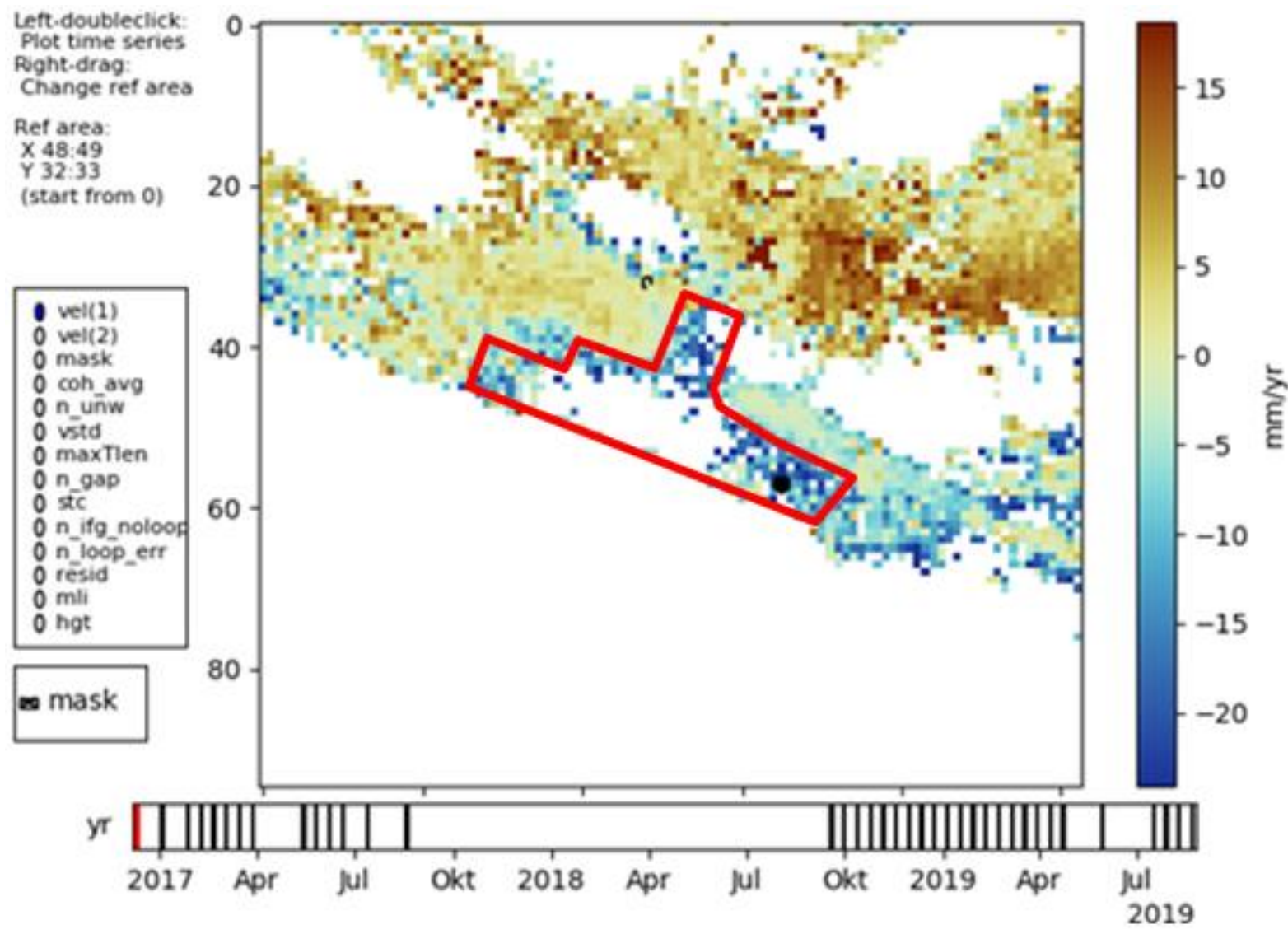

Figure 6. The Deformation Velocity Maps around the YIA Area. Red Area Shows the YIA Area.

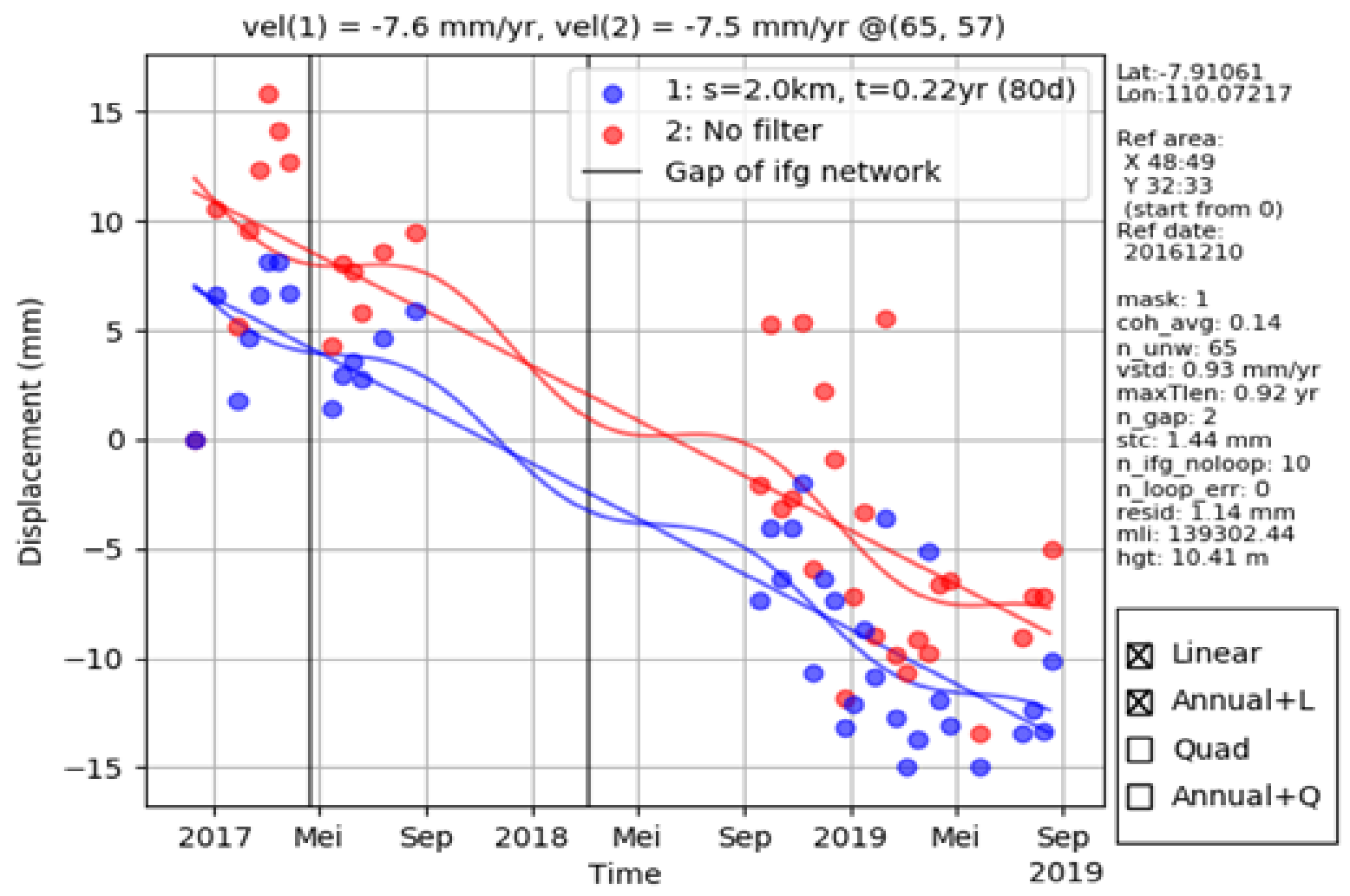

Figure 7. The Time Series of Deformation Map Shows Land Subsidence YIA 


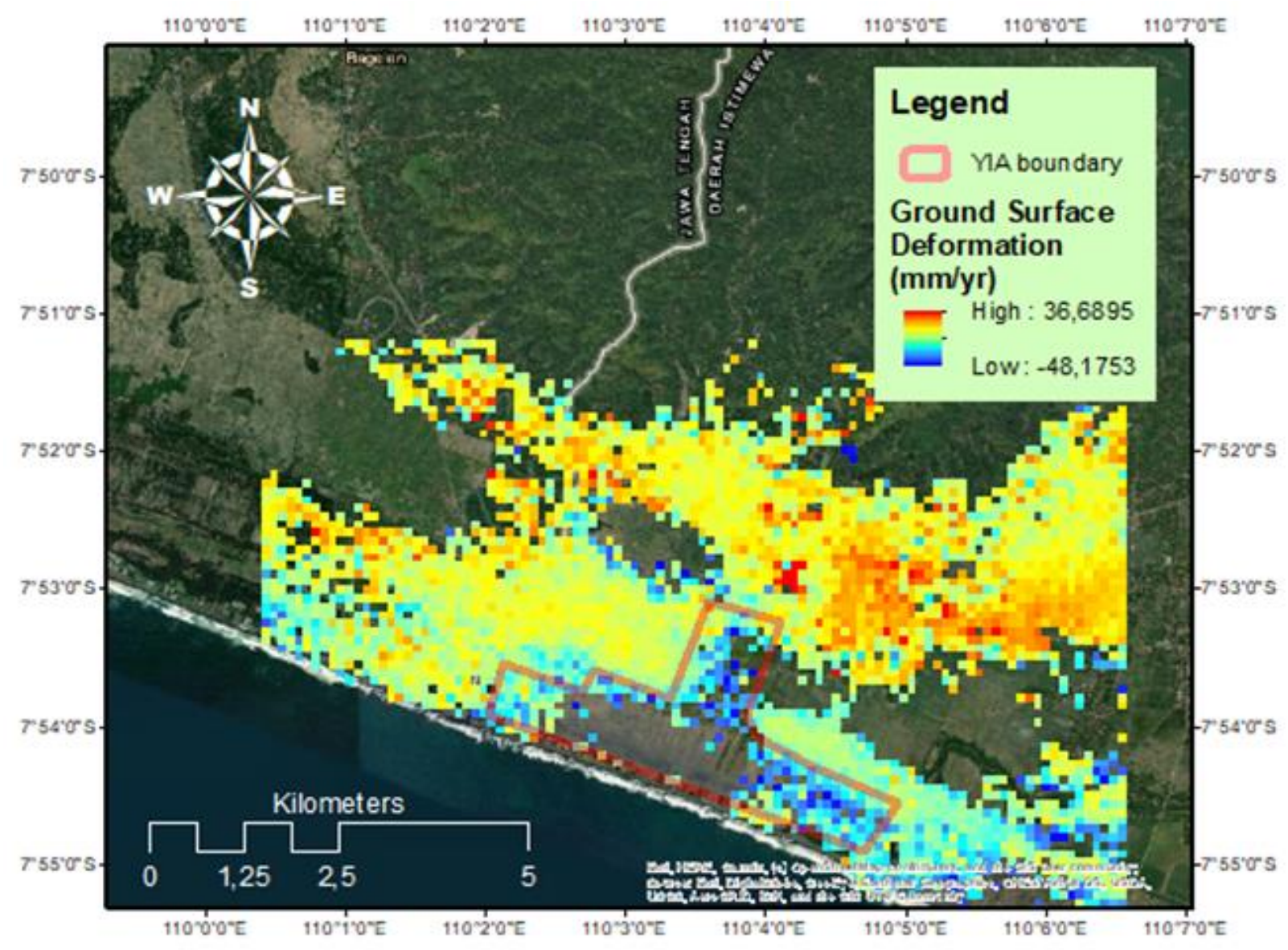

Figure 8. The Deformation Phenomenon with the Base Map. The Red Line Shows the YIA Boundary

\section{Conclusions}

The aim of this study was to monitor the deformations in the Yogyakarta International Airport (YIA) region. Uplift deformation occured in the northern part of YIA. However, the southern part (near to the beach) showed a dominance of land subsidence. The uplift deformation is affected by the Menoreh Mountains, while the land subsidence near to the beach is affected by the Sunda Megathrust activity, which subducts under the Eurasian Plate. The time series shown in Figure 7, resulted in land subsidence of $\sim 25 \mathrm{~mm} / \mathrm{yr}$. The time series displays land subsidence. The deformation range observed in YIA is $-48 \mathrm{~mm} / \mathrm{yr}$ to 36 $\mathrm{mm} / \mathrm{yr}$, with a normal difference of $0.1 \mathrm{~mm} / \mathrm{yr}$. The deformation in the vicinity of the YIA area is important to understand, as this area is located near to the Indian Ocean and the Sunda Megathrust.

\section{Acknowledgments}

The authors would like to thank the LiCSBAS (managed by Centre for the Observation and Modelling of Earthquakes, Volcanoes and Tectonics), which gave permission to process the Sentinel-1 InSAR data in frame 076D_09725_121107.

\section{References}

1. Jarach, D., Future Scenarios for the European Airline Industry: A Marketing-based Perspective, Journal of Air Transportation, 9(2), 2004, pp. 2339.

2. Evans, N., Managing Airports: An International Perspective, International Journal of Tourism Research, 5, 2003, pp. 154.

3. BNPB, Indeks Risiko Bencana Indonesia, Direktorat Pengurangan Risiko Bencana Deputi Bidang Pencegahan dan Kesiapsiagaan, Jakarta, 2013.

4. Hanifa, N. R., Sagiya, T., Kimata, F., Efendi, J., Abidin, H. Z., and Meilano, I., Interplate Coupling Model of the Southwestern Coast of Java, Indonesia, Based on Continuous GPS Data in 2008-2010, Earth and Planetary Science Letters, 401, 2014, pp. 159-171, http://dx.doi.org/10.1016/ j.epsl.2014.06.010.

5. Kongko, W. and Hidayat, R., Earthquake-Tsunami in South Jogjakarta Indonesia: Potential, Simulation Models, and Related Mitigation Efforts, IOSR Journal of Applied Geology and Geophysics, 2(3), 2014, pp. 18-22. 
6. Koulali, A., McClusky, S., Susilo, S., Leonard, Y., Cummins, P., Tregoning, P., and Wijanarto, A. B., The Kinematics of Crustal Deformation in Java from GPS Observations: Implications for Fault Slip Partitioning, Earth and Planetary Science Letters, 458, 2017, pp. 69-79.

7. Liu, G., Luo, X., Chen, Q., Huang, D., and Ding, $\mathrm{X}$., Detecting Land Subsidence in Shanghai by PS-networking SAR Interferometry, Sensors, 8(8), 2008, pp. 4725-4741.

8. Chen, M., Tomás, R., Li, Z., Motagh, M., Li, T., Hu, L., Gong, H., Li, X., Yu, J., and Gong, X., Imaging Land Subsidence Induced by Groundwater Extraction in Beijing (China) Using Satellite Radar Interferometry, Remote Sensing, 8, 2016, pp. 468.

9. Ishitsuka, K., Tsuji, T., Matsuoka, T., Nishijima, J., and Fujimitsu, Y., Heterogeneous Surface Displacement Pattern at the Hatchobaru Geothermal Field Inferred from SAR Interferometry Time-series, International Journal of Applied Earth Observation and Geoinformation, 44, 2016, pp. 95-103.

10. Da Lio, C. and Tosi, L., Land Subsidence in the Friuli Venezia Giulia Coastal Plain, Italy: 19922010 Results from SAR-based Interferometry, Science of the Total Environment, 633, 2018, pp. 752-764.

11. Chaussard, E., Wdowinski, S., Cabral-Cano, E., and Amelung, F., Land Subsidence in Central Mexico Detected by ALOS InSAR Time-series, Remote Sensing of Environment, 140, 2014, pp. 94-106.

12. Ng, A.H.M., Ge, L., Li, X., Abidin, H.Z., Andreas, H., and Zhang, K., Mapping Land Subsidence in Jakarta, Indonesia Using Persistent Scatterer Interferometry (PSI) Technique with ALOS PALSAR, International Journal of Applied Earth Observation and Geoinformation, 18, 2012, pp. 232-242.

13. Zhao, F., Mallorqui, J., Iglesias, R., Gili, J., and Corominas, J., Landslide Monitoring Using Multi-Temporal SAR Interferometry with Advanced Persistent Scatterers Identification Methods and Super High-Spatial Resolution TerraSAR-X Images, Remote Sensing, 10, 2018, pp. 921.

14. Atzori, S., Hunstad, I., Chini, M., Salvi, S., Tolomei, C., Bignami, C., Stramondo, S., Trasatti, E., Antonioli, A., and Boschi, E., Finite Fault Inversion of DInSAR Coseismic Displacement of the 2009 L'Aquila Earthquake (Central Italy), Geophysical Research Letters, 36(L15305), 2009.

15. Lanari, R., Casu, F., Manzo, M., and Lundgren, P., Application of the SBAS-DInSAR Technique to Fault Creep: A Case Study of the Hayward Fault, California, Remote Sensing of Environment, 109, 2007, pp. 20-28.

16. Manunta, M., Marsella, M., Zeni, G., Sciotti, M., Atzori, S., and Lanari, R., Two-scale Surface Deformation Analysis Using the SBAS-DInSAR
Technique: A Case Study of the City of Rome, Italy, International Journal of Remote Sensing, 29(6), 2008, pp. 1665-1684.

17. Zeni, G., Bonano, M., Casu, F., Manunta, M., Manzo, M., Marsella, M., Pepe, A., and Lanari, R., Long-term Deformation Analysis of Historical Buildings Through the Advanced SBAS-DInSAR Technique: The Case Study of the City of Rome, Italy, Journal of Geophysics and Engineering, 8(3), 2011, pp. S1-S12.

18. Xu, B., Feng, G., Li, Z.-W., Wang, Q., Wang, C., and Xie, R., Coastal Subsidence Monitoring Associated with Land Reclamation Using the Point Target Based SBAS-InSAR Method: A Case Study of Shenzhen, China, Remote Sensing, 8, 2016, pp. 652.

19. Ng, A.H.M., Ge, L., Li, X., Abidin, H.Z., Andreas, H., and Zhang, K., Mapping Land Subsidence in Jakarta, Indonesia Using Persistent Scatterer Interferometry (PSI) Technique with ALOS PALSAR, International Journal of Applied Earth Observation and Geoinformation, 18, 2012, pp. 232-242.

20. Radhi, A.A.B.M., Monitoring Land Subsidence of Airport using InSAR Timeseries Techniques with Atmospheric and Orbital Error Corrections, Thesis, Universiti Teknologi Malaysia, 2017.

21. Morishita, Y., Lazecky, M., Wright, T.J., Weiss, J.R., and Elliott, J.R., LiCSBAS: An Open-Source InSAR Time Series Analysis Package Integrated with the LiCSAR Automated Sentinel-1 InSAR Processor, Remote Sensing, 12, 2020, pp. 424.

22. Yu, C., Li, Z., Penna, N.T., and Crippa, P., Generic Atmospheric Correction Model for Interferometric Synthetic Aperture Radar Observations, Journal of Geophysical Research: Solid Earth, 123, 2018, pp. 9202-9222.

23. Scheiber, R. and Moreira, A., Coregistration of Interferometric SAR Images Using Spectral Diversity, IEEE Transactions on Geoscience and Remote Sensing, 38, 2000, pp. 2179-2191.

24. Schmidt, D.A. and Bürgmann, R., Timedependent Land Uplift and Subsidence in the Santa Clara Valley, California, From A Large Interferometric Synthetic Aperture Radar Data Set, Journal of Geophysical Research: Solid Earth, 108, 2003, pp. 1-13.

25. Agram, P., Jolivet, R., and Simons, M., Generic InSAR Analysis Toolbox (GIAnT)-User Guide, 2012, retrieved from http://earthdef.caltech.edu.

26. Hooper, A.J., Bekaert, D., Spaans, K., and Arikan, M., Recent Advances in SAR Interferometry Time Series Analysis for Measuring Crustal Deformation, Tectonophysics, 514-517, 2012, pp. 1-13.

27. Fauzi, Y., Hartono, Brotopuspito, K.S., and Kongko, W., Use of Small Format Aerial Photograph for Environmental Vulnerability Identification of Tsunami Disaster at Yogyakarta International Airport (YIA), Geomatika, 25, 2019, pp. 63-72. 